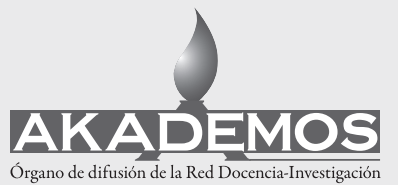

ISSN: 1995-4743

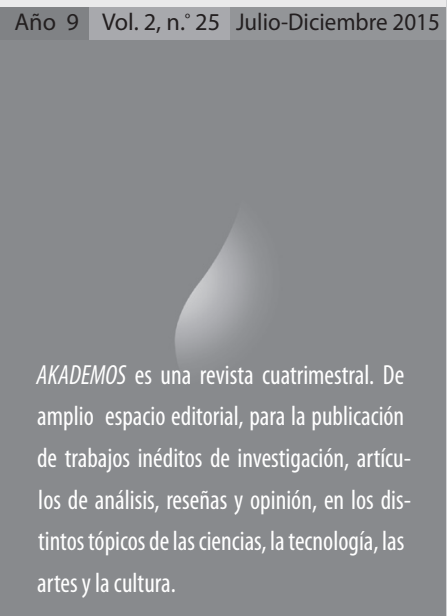

San Salvador, El Salvador, Centroamérica
Melius est reprehendant nos gramatici quam non intelligant populi

San Agustín

\title{
Aspectos de la morfología del verbo latino y su relación con el verbo español
}

\author{
David E. López \\ Investigador Centro de Investigaciones en Ciencias y Humanidades, $\mathrm{CICH}$. \\ davidelopez@hotmail.com
}

Fecha de recepción 21/09/2015 - Fecha de aceptación: 21/10/2015

\section{Abstrac}

The so-called neolatin languages o Romanic ones are the result of a development process, that goes from vulgar Latin or spoken Latin to independent languages. This process started with the falling of the Roman Empire; afterwards the spoken Latin of the former Roman provinces begun to acquire its own features, far away from a unique political center. In this manner French, Italian and Spanish were emerging, among other neolatin languages.

Even though we talk about neolatin languages as a new linguistic phenomenon, it is still remarkable in them a deep track of the mother language. This mark goes beyond lexical and phonetic aspects, which are more visible. One of the deepest mark can be found in the morphology of the verb in the neolatin languages, of which we can say that the form of the Latin verb was kept with great allegiance, as we can see in the case of the Spanish verb.

\section{Resumen}

Las así llamadas lenguas neolatinas o romances son el resultado de un proceso de desarrollo del latín vulgar o latín hablado que, luego de la caída del Imperio romano, fue adquiriendo sus propias características en las diferentes ex colonias hasta convertirse en lenguas independientes. De esta forma surgió el francés, el italiano y el español, entre otras lenguas neolatinas. 
Si bien cuando hablamos de lenguas neolatinas tratamos de un fenómeno lingüístico nuevo, es observable todavía en ellas la huella profunda de la lengua madre, y esta huella va más allá de aspectos visibles como el léxico o la fonética. Una de las huellas más profundas de la lengua madre se encuentra en la morfología del verbo de las lenguas romances que, en términos generales, conservó con bastante fidelidad el verbo latino, como puede observarse en el caso concreto del verbo español.

Palabras claves: morfología, aoristo, lexema, tema, deponente, conjugación, flexión, modo, tiempo, aspecto, indoeuropeo, romance, neolatino, morfema, desinencia.

\section{Introducción}

Los estudios diacrónicos de la lengua española tuvieron un gran apogeo en finales del siglo XIX y durante la primera mitad del XX, impulsados por los hallazgos de la gramática comparada. Los mismos, actualmente, parecen haber caído en desuso, corriendo con ello la misma suerte que estudios históricos y clásicos de otras áreas del conocimiento, que han sido sacrificados en aras de lo contemporáneo, lo tangible, lo inmediato, lo útil. En esta búsqueda de la utilidad estamos a punto de caer, no obstante, en una condición cultural peligrosamente ignara.

Pese a lo anterior, es necesario afirmar una vez más la necesidad de ir a las fuentes; si bien el estudio de las mismas no puede ser visto con petulancia intelectual, como pura curiosidad o como el examen de una pieza de museo que nada tiene que ver con nuestro presente.

Por todo ello, el estudio de la morfología del verbo latino y su relación con el español quiere reivindicar el valor del estudio de lo clásico y de las fuentes de nuestra cultura, sin pretender menoscabar los estudios sincrónicos y sin negar validez a otros enfoques. Simplemente decimos que es un enfoque necesario.

El estudio no es exhaustivo. Conscientemente se omiten aspectos del verbo, como clasificaciones según su conjugación, su significado y su origen, entre otros aspectos. Esto nos permite hacer el trazo fundamental de la morfología del verbo.

\section{Parte primera: el verbo latino}

\section{La hipótesis del indoeuropeo}

La hipótesis que sostiene que el sánscrito, el griego y el latín son lenguas afines y tienen un origen común es una de las grandes contribuciones científicas de William Jones (1746-94), un gran orientalista inglés. A este origen común es a lo que llamamos indoeuropeo.

Con el desarrollo de la así llamada gramática comparada, en el siglo XVIII, nuevos miembros se fueron agregando a la familia indoeuropea, entre los que tenemos el germánico, el eslavo y el iranio.

El concepto de indoeuropeo se refiere, según Monteil (2003: 28), "a la lengua común a 
partir de la cual algunas alteraciones particularizadoras han dado lugar a las lenguas indoeuropeas conocidas". Hay que aclarar, no obstante, que no conocemos esa lengua ni tenemos escrito alguno de ella; pero sí conocemos a su numerosa descendencia.

Watkins (1995: 57), por su parte, define al indoeuropeo de la siguiente manera:

Indoeuropeo es el nombre que por razones geográficas se asigna a una familia lingüistica amplia y genéticamente bien definida, que comprende la mayor parte de las lenguas de Europa, antiguas y actuales, y que se extiende hasta la mitad septentrional del continente indio, a través de Irán y de Afganistán.

Para Monteil (2003: 29), indoeuropeo es una noción puramente lingüística; esto es, no sirve más que para designar una lengua que está detrás de un conjunto de ecuaciones lingüisticas. Estas ecuaciones podrían expresarse así: entre lenguas como el griego, el latín y el sanscrito "existen una serie de correspondencias". Entre estas Monteil menciona una serie de números y nombres del campo familiar.

En el caso de los números, podemos ver sus correspondencias en el siguiente cuadro:

Tabla 1: Los números en el indoeuropeo

\begin{tabular}{|c|c|c|c|}
\hline Número (Español) & Latín & Griego & Sánscrito \\
\hline Tres & Tres & $T \varrho \tilde{\varepsilon} \iota \varsigma$ (treis) & Tráyah \\
\hline Cuatro & Quattor & $\tau \varepsilon ́ \tau \tau \varrho \alpha \varrho \varepsilon \varsigma$ (téttrares) & Qatvárah \\
\hline Cinco & Quinque & $\Pi \tilde{\varepsilon} v \tau \varepsilon$ (pénte) & Pánca \\
\hline Siete & Septem & $\dot{\varepsilon} \pi \tau \dot{\alpha}$ (heptá) & Saptá \\
\hline
\end{tabular}

En términos geográficos, el indoeuropeo se entendía desde la Península India hasta el Atlántico; mientras que en términos temporales podría situarse en el tercer milenio a. C. (Monteil, 2003)
En el caso de nombres de parentesco, pueden observarse las correspondencias en el siguiente cuadro:

\section{Tabla 2: Los nombres de parentesco en el indoeuropeo}

\begin{tabular}{|c|c|c|c|}
\hline Nombres (Español) & Latín & Griego & Sánscrito \\
\hline Padre & Pater & $\pi \alpha \tau \dot{\eta} \varrho$ (patēr) & Pitár \\
\hline Progenitor & Genitor & $\gamma \varepsilon v \varepsilon ́ \tau \omega \varrho$ (genétōr) & Janitr \\
\hline Madre & Mater & $\boldsymbol{\mu} \dot{\eta} \tau \eta \varrho$ (mētēr) & Matar \\
\hline Hermano & Frater & $\dot{\alpha} \delta \varepsilon \lambda \varphi \boldsymbol{\varphi} \varsigma$ (adelphós) & bhrátar \\
\hline
\end{tabular}


Para explicar estas correspondencias, según Monteil (2003), debe excluirse el así llamado préstamo lingüistico, sobre todo porque su distancia geográfica y cronológica lo habrían impedido. Tampoco es posible explicar por la vía del azar. La única explicación posible es el "origen común".

Tomemos un ejemplo que suele aducirse para explicar la idea del indoeuropeo. Imaginemos que desconocemos una lengua llamada latín. Pero en nuestros estudios de las lenguas romances observamos que entre ellas existe una extraña relación de afinidad. ${ }^{1}$ Concluimos, en nuestro análisis comparativo, que ninguna de las lenguas neolatinas pudo copiar a otra contemporánea o generarse a partir de una de ellas. Entonces llegamos a una hipótesis genética: todas ellas debieron haber tenido un tronco común del cual derivan; ese origen común ciertamente no lo conocemos, pero eso no es razón suficiente para negar su existencia. A ese tronco común le llamamos latín. Luego, al cabo de unos años, un estudioso de la historia del romance descubre escritos en latín, la lengua que origina todos los romances; entonces, encontramos elementos empíricos de nuestra hipótesis, de algo que ya sabíamos. Algo parecido es lo que sucedió con el indoeuropeo.

\section{El latín, lengua indoeuropea}

El latín es, en su origen, la lengua de una comarca situada junto al Tíber, en la región de la Lacio. Con el crecimiento y la expansión de Roma llegó a convertirse en una lengua que traspasó los límites de la península itálica, difundiéndose por toda Europa, y más allá de sus confines.

Según Tagliavini (1973), la expansión del latín por el vasto territorio que abarcó el Imperio trajo como consecuencia, primero, que ejerció una gran influencia -y también la padeció - sobre las lenguas de los diferentes pueblos y, segundo, el latín pasó de ser una lengua relativamente unitaria en Roma a convertirse en una lengua que se fue diferenciando en las distintas regiones. Añade el gran filólogo italiano que estas diferencias fueron limitadas y controladas mientras existía un fuerte nexo de las provincias con la metrópoli; pero con la caída del Imperio y su disolución política, las diferencias se ahondaron hasta el surgimiento de las lenguas neolatinas o romances.

A las provincias romanas llegó el latín en sus variadas formas. Como nos informa Lapesa (1973), por un lado llegó el latín literario a través de sus poetas y sabios; ${ }^{2}$ pero también el así llamado sermo vulgaris o latín vulgar, que no es otra cosa que la lengua hablada por los diversos sectores sociales; y que también recibe los nombres de sermo plebeius o sermo cotidianus (Obediente Sosa, 2000: 28).

1 A propósito del uso del término afinidad 0 al de parentesco, Tagliavini (1973) afirma que es preferible hablar de lenguas afines, en lugar de parentesco.

2 Una evidencia de que en las provincias estaba en uso el latín literario lo tenemos claramente en España: Quintiliano (siglo I d. C.), el gran retórico romano después de Cicerón, es de origen español. 
Es obvio que con la caída del Imperio, la desaparición de una metrópoli que sirviera de unidad política y lingüística, la pérdida de todos los logros del Imperio en materia científica, artística y educativa, originó que cada ex provincia siguiera su propio rumbo político, y también en su desarrollo lingüístico, en el cual prevaleció el latín vulgar que, con el tiempo, dio lugar a lo que conocemos hoy lenguas romances. En otras palabras, el español -y con él todas las lenguas romances- surgen como una evolución del latín vulgar o de una especie de lengua común o koiné latina. (Tagliavini, 1973). Obediente Sosa (2000: 30) explica este proceso de la siguiente manera:

Las grandes innovaciones experimentadas por el latín vulgar van a alcanzar su apogeo una vez el Imperio desmembrado; la lengua hablada en cada provincia va a dar rienda suelta a sus propias tendencias sin que haya nada que las frene; el resultado será la fragmentación lingüística de la Romania y la subsiguiente aparición de las lenguas romances. Estas lenguas son, por tanto, la continuación no tanto del latín literario o lengua clásica como del latín popular o vulgar. (...)

En este mismo tópico, Menéndez Pidal (1905) afirma que tras el desmembramiento del Imperio se siguió usando el latín en gran parte del mismo, pero especialmente en la región occidental. Esto sucedió muy a pesar de las invasiones de pueblos extraños, sobre todo los bárbaros. Anota el sabio español que el latín se siguió hablando de manera alterada y diversa en cada provincia.
Menéndez Pidal (1905: 8) concluye que nuestra lengua, además de derivar del latín vulgar, es un hecho todavía más complejo:

Pero si el latín vulgar explica la parte más grande y castiza de la lengua española, no puede explicarla toda. Gran porción de nuestro idioma, como de todos los romances, procede del latín literario.

El griego y el latín forman parte de las así llamadas lenguas de flexión, es decir, lenguas que expresan las relaciones de las categorías como sustantivos, determinantes, adjetivos, participios y gerundios mediante cambios, alteraciones o quiebres morfológicos, y no mediante el orden de la oración, como sucede en nuestra lengua y en el resto del romance. En resumen, expresan las relaciones sintácticas mediante la forma de las palabras. (Martínez Bigorra, 1976)

Un ejemplo nos ayudará a entender lo anterior. En la oración simple en español yo tengo un perro, tomemos el sustantivo perro. Del mismo podríamos decir que es el objeto directo de la oración, y que completa la acción del verbo transitivo activo tengo. ¿Cómo sabemos que es el objeto directo? En general, lo sabemos por el orden de la oración: sucede al verbo tener y sobre aquel recae la acción directa del verbo. No sabemos que es objeto directo por marcas morfológicas que tenga la palabra perro que nos lo indiquen; de esta manera, la forma perro no sufre alteraciones si es sujeto (el perro tiene hambre), si es objeto indirecto (di un hueso al perro), o si está en aposición (tengo hambre de perro). 
En cambio, para expresar las relaciones anteriores en latín, la palabra perro tendría que sufrir alteraciones morfológicas que indiquen su función en la oración. Si digo tengo un perro, el latín escribiría canem habeo (el perro/canem como objeto directo va en el caso llamado acusativo); pero si dijera el perro tiene hambre, podría escribir canis famem habet (el perro/canis como sujeto de la oración, el caso llamado nominativo); pero también famem canis habet y canis habet famem, entre otras. Con razón, Vineis (1995: 395) afirma que en cuanto al orden de los constituyentes de la frase en latín en la época clásica "es totalmente libre y admite todas las combinaciones", aunque hay una cierta preferencia por el orden sujetoobjeto-verbo, al igual que en griego.

No obstante todas las posibles combinaciones, el significado seguiría siendo el mismo, como en nuestra oración a propósito del perro. Nótese que la palabra perro, canis, sufre alteraciones que indican su función en la oración; esta función la indican sus cambios morfológicos, no su posición en la oración. Pero esto solo sucede en la oración en latín y en griego, no en español.

En suma, los sustantivos alteran su forma $-\mathrm{y}$ las otras formas ya mencionadas- según su función en la oración o en el discurso. Por eso decimos que el latín, también el griego, es lengua de flexión. Esta diferencia radical entre la sintaxis del latín y la de las lenguas romances es de suma importancia:

La mayor diferencia entre la sintaxis del latín clásico y la de las lenguas neolatinas es, de cierto, la distinta colocación de las palabras en el periodo; la relativa libertad del periodo latino la sustituye un orden fijo. (Tagliavini, 1973: 320)

A los diferentes cambios o alteraciones morfológicas que sufren los sustantivos, los determinantes, las formas pronominales, los adjetivos y algunas de las formas no personales del verbo en las diversas relaciones que expresan en la sintaxis latina se les conoce con el nombre de declinación, de las cuales la lengua de Horacio conoce cinco modelos o paradigmas para declinar todas esas formas lingüísticas.

\section{Descripción general del verbo latino}

Cuando hablamos de las diferentes transformaciones que sufre el verbo en su proceso de significación, es preferible que las mismas sean llamadas conjugación, y no flexión verbal, como algunos suelen llamarla. ${ }^{3}$ Los verbos no se flexionan, sino que se conjugan.

Los sustantivos y las demás formas declinables en latín se clasifican según su terminación o desinencia en el caso llamado genitivo singular, con esta información sabemos a qué paradigma pertenece una forma, y a partir de aquí podemos declinarla. En el verbo, en cambio, sabemos a qué paradigma o conjugación pertenece determinada forma cuando observamos la terminación o desinencia del infinitivo presente (Kinchin, 1982). Así, decimos que laudāre pertenece $^{-}$

3 Encontramos ejemplos en casi todas las gramáticas.

4 Alabar, venerar. 
a la primera conjugación (por su terminación en -āre, a larga), monēre ${ }^{5}$ a la segunda (por su terminación en -ēre, e larga), legěre ${ }^{6}$ a la tercera (por su terminación en -ĕre, $e$ breve), y audīre a la cuarta (por su terminación en -îre, $i$ larga).

En todo verbo es posible encontrar seis accidentes gramaticales: ${ }^{8}$ modo, voz, tiempo, aspecto, persona y número. De estos accidentes, solo el número no es propio del verbo; los cinco restantes son los que lo diferencian de una forma nominal, que es aquella con la que más se asemeja el verbo. ${ }^{9}$

El sustantivo, en cambio, presenta accidentes propios que lo diferencian de otras formas en latín: caso y género. No así el número, que es común a ambos y a otras formas. Es un lugar común, no obstante, una distinción muy clara entre verbo y sustantivo: el primero designa acciones, existencia y procesos; mientras que el segundo objetos o cualidades.

La noción de modo del verbo nos indica, en general, la perspectiva del hablante en cuanto a lo que expresa la forma verbal, a saber, el modo expresa la subjetividad del hablante en su consideración de la semántica verbal. Por eso es posible hablar del proceso verbal como real u objetivo, deseado o posible. Cuando el proceso verbal es considerado como real, tenemos el modo indicativo; en cambio, los modos subjuntivo e imperativo expresarían procesos verbales considerados como posibles, deseables o probables.

Lázaro y Tusón (1989: 57) piensan que el modo es la categoría verbal que "permite al hablante hacer notar su actitud personal ante la acción". Cuando esta acción es presentada objetivamente, "como un hecho independiente de sus sentimientos", tenemos el modo indicativo (Tomás vino ayer). Por otro lado, cuando el hablante la presenta subjetivamente, es decir, "con un sentimiento personal de duda, temor, deseo, etc.", estamos ante el modo subjuntivo (quizás venga Tomás boy); por último, cuando el hablante presenta la acción "como una orden que da al oyente", tenemos el modo imperativo (¡Tomás, ven!).

¿Cuántos modos verbales tenemos en latín? Contamos claramente con los tres ya mencionados -indicativo, subjuntivo e imperativo-; en griego, en cambio, se puede hablar con propiedad de un modo optativo. Contamos, además, con las formas no personales o nominales: infinitivo, participio, gerundio (forma sustantivable), gerundivo (forma adjetivable) y el supino. No olvidemos que varios estudiosos del griego helenístico, entre ellos Zerwick (1974), considera modos a algunas de las así llamadas formas nominales del verbo, en concreto, al infinitivo y al participio.

En cuanto a voz, en latín existen claramente la voz activa y la pasiva; esta última como una forma sintética, y no perifrástica, como

\footnotetext{
Advertir.

Leer.

Escuchar

También suelen ser llamados accidentes verbales.

De hecho, en algunas ocasiones resulta difícil distinguir una forma verbal de una nominal. Por ejemplo, screw 0 draw, en inglés. ¿Cuándo se refieren a un sustantivo y cuándo a un verbo? 0, en español, cant-o (verbo) y canto (sustantivo); así como grit-o (verbo) y grito (sustantivo).
} 
sucede en las lenguas occidentales modernas. En latín yo puedo decir, por ejemplo, laud$o$, yo alabo, donde el sujeto gramatical es el agente de la acción verbal. Pero puedo decir, también, laud-or, soy alabado, donde el sujeto del verbo no es el agente de la acción, sino que la padece. En el primero de estos casos hablamos de voz activa, mientras que en el segundo hablamos de pasiva. Esta última se expresa en latín con una forma verbal, y no con una perífrasis, circunloquio o rodeo.

Pero en la voz latina encontramos otro aspecto desconocido en español y en las lenguas occidentales modernas: los verbos deponentes. ¿Qué es un verbo deponente? Se trata de verbos que desde un punto de vista morfológico se presentan únicamente en la voz pasiva, pero que su significado es activo. Incluso en los tiempos compuestos o perifrásticos se debe tener mucho cuidado en la traducción de estos verbos. Así, el verbo hortor significa yo exhorto; pero si yo digo hortatus sum, esto no debe ser traducido como un pasivo perifrástico (yo soy exhortado), sino de manera activa, esto es, debe traducirse como un perfecto activo: yo he exhortado. (Kinchin, 1948; Janssens, 1990; Monteil, 2003)

Por ejemplo, el verbo misereor ${ }^{10}$ está morfológicamente en la voz pasiva, pero su significado es activo: yo tengo compasión; lo mismo podría decirse de furor, yo robo. Este mismo fenómeno lo encontramos en griego. A este respecto, Menéndez Pidal (1905: 178) anota:

El verbo latino ya representaba un estadio empobrecido del verbo indoeuropeo, pues carecía de la voz. media, del modo optativo, del número dual; conti- nuó empobreciéndose en el latín vulgar, sustituyendo varias formas sintéticas por otras analiticas.

Pierre Monteil (2003) habla también de la vOz impersonal, y por ella entiende aquella "desprovista de autonomía morfológica" (pluit, llueve; tonat, truena, etc.).

El tiempo de la acción verbal en latín puede ser categorizado en tres: pasado, presente y futuro. ${ }^{11}$ La idea de tiempo de la acción verbal -tense, en inglés- no puede ser separada de la idea de aspecto de la acción. En este punto, Monteil (2003) anota que las lenguas occidentales modernas conceden un gran espacio a la noción de tiempo, pero que esto no era así en el indoeuropeo, donde la oposición fundamental era en torno a la perspectiva de aspecto.

La categoría de tiempo verbal en latín, en suma, es definida de la siguiente manera:

La noción de tiempo verbal consiste en localizar el proceso en su duración, representada en forma de una linea continua, sobre la cual una marca determina, a un lado y otro de sí misma, una duración pasado y una duración por venir. Esta marca corresponde generalmente al instante de la duración en que se sitúa el acto del habla, y equivale al presente del bablante. (...) (Montiel, 2003: 305)

10 Desde un análisis estrictamente morfológico, tanto misereor como furtor son indicativo presente pasivo, primera persona singular; pero desde un punto de vista semántico son activos. No es posible encontrar las formar miserere y furtare, que serían las formas esperadas del infinitivo presente activo correspondiente.

11 En griego tenemos un tiempo adicional: el aoristo, que señala una acción terminada en un tiempo remoto con respecto al presente del hablante. 
Al referirnos a aspecto, según Monteil (2003), no se sitúa un proceso por referencia al momento en que se produce el acto del habla, "sino por una especie de referencia interna al proceso mismo". En otras palabras, cuando hablamos de aspecto nos referimos a la acción en términos de un proceso a punto de acabarse, en su comienzo, mientras dura, en su término, acabado, etc. El aspecto en latín está contenido en los procedimientos morfológicos, mientras que en otras lenguas se hace mediante palabras que se añaden al verbo.

Cuando decimos, por ejemplo, laudābo (yo alabaré), que en latín es un indicativo imperfecto activo, de la primera persona singular, nos referimos a una acción que se realizará en el futuro, con respecto al presente del hablante; y hasta aquí tenemos con ello la idea de tiempo. Pero la forma verbal es también imperfecta, y con ello señalamos características específicas de la acción, la cual es considerada inconclusa o no acabada; con ello tenemos la idea de aspecto de la acción que, como decíamos, es inseparable de la idea de tiempo. De ahí que podamos hablar de aspectos de la acción, y esto lo hacemos con las categorías de perfecto, pluscuamperfecto e imperfecto.

\section{Las conjugaciones latinas}

La mayoría de latinistas habla de cuatro conjugaciones, las que son conocidas como primera conjugación (verbos terminados en āre en el infinitivo presente activo, laud-āre ), segunda conjugación (verbos terminados en -ēre en el infinitivo presente activo, monēre ), tercera conjugación (verbos terminados en - ere en el infinitivo presente activo, legere) y cuarta conjugación (verbos terminados en -īre en el infinitivo presente activo, audīre). Así también, hay quienes identifican una quinta conjugación, a la que llaman mixta; esta conjugación sería una especie de fusión de la tercera y la cuarta, y el verbo que la representaría muy bien sería capēre (tomar, capturar). (Janssens, 1990; Martínez Bigorra, 1976)

En cualquier forma verbal encontramos un tema, constituido por una parte invariable del verbo en determinada parte de la conjugación, y unas desinencias o morfemas, que nos dan información gramatical del verbo, tales como: modo, voz, tiempo, aspecto, persona y número.

En el infinitivo laudare, por ejemplo, laudsería el lexema, el cual nos da información sobre el significado del verbo. -are, en cambio, serían las desinencias o morfemas que, en este caso, podrían ser descompuestas en: $-a-$, que nos da información sobre la conjugación a la que pertenece el verbo, que en nuestro caso se trata de la primera. Este morfema suele ser llamado vocal temática. El morfema -re nos informa sobre el modo y el tiempo del verbo, en este caso nos dice que se trata de un infinitivo presente activo.

En la medida en que el verbo se conjuga, entre el lexema y los morfemas se añaden algunos infijos invariables para determinadas formas del verbo. De esta manera, el lexema es modificado parcial o totalmente. A este lexema modificado para ciertas partes de la conjugación solemos llamarlo tema (stem, en 
inglés). ${ }^{12}$ Por ejemplo, para todas las formas perfectivas de la primera conjugación, el lexema es modificado mediante la adición de una $-\nu$ - que indica perfecto; en nuestro caso, laud- se convierte en laudav-. De igual modo, para todas las formas imperfectas de la primera conjugación, el lexema laud- se convierte en laudab-; esta $-b$ - interpuesta entre el lexema y los demás morfemas indicaría, entonces, imperfección de la acción expresada por el verbo. Así, decimos que el tema del imperfecto en la primera conjugación es laudab-; esto es válido tanto para la voz activa como para la pasiva.

\section{Tabla 3: La primera conjugación: laudāre (voz activa)}

\begin{tabular}{|c|c|c|}
\hline Modo indicativo & Latín & Español \\
\hline \multirow{6}{*}{ Presente } & laud -ō & alab-o \\
\hline & -ās & -as \\
\hline & -at & $-a$ \\
\hline & -āmus & -amos \\
\hline & -ātis & -áis \\
\hline & -ant & -an \\
\hline \multirow[t]{6}{*}{ Pretérito imperfecto } & laud-ābam & alab-aba \\
\hline & -ābās & -abas \\
\hline & -ābat & -aba \\
\hline & -ābamus & -abamos \\
\hline & -ābātis & -abáis \\
\hline & -ābant & -aban \\
\hline \multirow[t]{6}{*}{ Futuro imperfecto } & laud-ābo & alab-aré ${ }^{13}$ \\
\hline & -ābis & -arás \\
\hline & -ābit & -ará \\
\hline & -ābimus & -aremos \\
\hline & -ābitis & -aréis \\
\hline & -ābunt & -arán \\
\hline
\end{tabular}

Continua...

12 En los sustantivos cada uno suele tener un tema; en el verbo, en cambio, hay múltiples temas en el proceso de la conjugación.

13 Esta forma tendría su origen en cantare habeo, dicere habeo, que en un principio significaban he de cantar, tengo que decir. Poco a poco fue adquiriendo el significado de un futuro imperfecto, sustituyendo a amabo. 
Viene de página anterior

\begin{tabular}{|c|c|c|}
\hline Pretérito perfecto & $\begin{array}{l}\text { laudāv-ī } \\
\text {-istī } \\
\text {-it } \\
\text {-imus } \\
\text {-istis } \\
\text {-ērunt/ēre }\end{array}$ & $\begin{array}{l}\text { he alabado (forma } \\
\text { perifrásticas) }\end{array}$ \\
\hline $\begin{array}{l}\text { Pretérito } \\
\text { pluscuamperfecto }\end{array}$ & $\begin{array}{l}\text { laudāv-eram } \\
\text {-erās } \\
\text {-erat } \\
\text {-erāmus } \\
\text {-erātis } \\
\text {-erant }\end{array}$ & $\begin{array}{l}\text { había alabado } \\
\text { (forma perifrástica o } \\
\text { analítica) }\end{array}$ \\
\hline Futuro perfecto & $\begin{array}{l}\text { laudāv-erō } \\
\text {-eris } \\
\text {-erit } \\
\text {-erimus } \\
\text {-eritis } \\
\text {-erint }\end{array}$ & $\begin{array}{c}\text { alab-aré } \\
\text {-arás } \\
\text {-ará } \\
\text {-aremos } \\
\text {-aréis } \\
\text {-arán }\end{array}$ \\
\hline \multicolumn{3}{|l|}{ Modo imperativo } \\
\hline & $\begin{array}{c}\text { laud-ā'14 } \\
\text {-āte } \\
\text {-ātō } \\
\text {-antō }\end{array}$ & $\begin{array}{l}\text { alab-a } \\
\text { alab-ad }\end{array}$ \\
\hline \multicolumn{3}{|l|}{ Modo subjuntivo } \\
\hline Presente & $\begin{array}{l}\text { laud-em } \\
\text {-ēs } \\
\text {-et } \\
\text {-ēmus } \\
\text {-ētis } \\
\text {-ent }\end{array}$ & alab-e \\
\hline (Pretérito)Imperfecto & $\begin{array}{l}\text { laud-ārem } \\
\text {-ārēs } \\
\text {-āret } \\
\text {-ārēmus } \\
\text {-ārētis } \\
\text {-ārent }\end{array}$ & alab-are/ase ${ }^{15}$ \\
\hline
\end{tabular}

Continua...

14 En latín tenemos un imperativo para la tercera persona, singular y plural, pero esto se perdió en el romance. Sólo en el imperativo no se conservaron todas las personas latinas: Las personas latinas se conservaron todas, salvo la tercera persona del imperativo: amäto, amanto (sustituidas por el presente subjuntivo ame, amen), y las enfáticas de la segunda persona: amato, amatōte.

15 Desde un punto de vista morfológico, el subjuntivo alabase tiene mucho de parecido con el subjuntivo pluscuamperfecto latino: amāvissem 
Viene de página anterior

\begin{tabular}{|c|c|c|}
\hline Perfecto & $\begin{array}{l}\text { laudāv-erim } \\
\text {-erīs } \\
\text {-erit } \\
\text {-erimus } \\
\text {-eritis } \\
\text {-erint }\end{array}$ & \\
\hline Pluscuamperfecto & $\begin{array}{c}\text { laudāv-issem } \\
\text {-issēs } \\
\text {-isset } \\
\text {-issēmus } \\
\text {-issētis } \\
\text {-issent }\end{array}$ & \\
\hline Infinitivo presente & laud-āre & alab-are \\
\hline Infinitivo perfecto & laudāv-isse & \\
\hline Participio presente & laudans & \\
\hline Gerundio & laudandum & Alabando \\
\hline Primer supino & laudāt-um & \\
\hline Segundo supino & laudāt-ū & \\
\hline Participio futuro & laudāt-ūrus & \\
\hline
\end{tabular}

Tabla 4: La primera conjugación: laudāre (voz pasiva)

\begin{tabular}{lcc}
\hline Modo indicativo & Latín & Español \\
\hline Presente & laud -or & \\
& -āris & \\
& -ātur & -āmur \\
& -āmini & -antur \\
Pretérito imperfecto & Laud -ābar \\
& -ābāris \\
& -ābātur \\
& -ābāmur \\
-ābāminī & -ābantur \\
Futuro imperfecto & Laud -ābor \\
& -āberis \\
& -ābitur \\
& -ābimur \\
& -ābiminī \\
& -ābuntur
\end{tabular}

Continua... 
Viene de página anterior

\begin{tabular}{|c|c|}
\hline Pretérito perfecto & $\begin{array}{l}\text { laudātus sum } \\
\text { es } \\
\text { est } \\
\text { laudati sumus } \\
\text { estis } \\
\text { sunt }\end{array}$ \\
\hline $\begin{array}{l}\text { Pretérito } \\
\text { pluscuamperfecto }\end{array}$ & $\begin{array}{l}\text { laudātus eram } \\
\text { erās } \\
\text { erat } \\
\text { laudāti erāmus } \\
\text { erātis } \\
\text { erant }\end{array}$ \\
\hline Futuro perfecto & $\begin{array}{l}\text { laudātus erō } \\
\text { eris } \\
\text { erit } \\
\text { laudātus erimus } \\
\text { eritis } \\
\text { erunt }\end{array}$ \\
\hline Modo imperativo & $\begin{array}{l}\text { Laud -āre } \\
\begin{array}{l}\text {-ātor } \\
\text {-āmini } \\
\text {-antōr }\end{array} \\
\begin{array}{l}\text { alab-a } \\
\text { alab-ad }\end{array}\end{array}$ \\
\hline \multicolumn{2}{|l|}{ Modo subjuntivo } \\
\hline Presente & $\begin{array}{l}\text { Laud -er } \\
\text {-ēris } \\
\text {-ētur } \\
\text {-ēmur } \\
\text {-ēminī } \\
\text {-entur }\end{array}$ \\
\hline Imperfecto & $\begin{array}{l}\text { Laud -ārer } \\
\text {-ārēris } \\
\text {-ārētur } \\
\text {-ārēmus } \\
\text {-ārēminī } \\
\text {-ārentur }\end{array}$ \\
\hline Perfecto & $\begin{array}{l}\text { laudātus sim } \\
\text { sis } \\
\text { sit } \\
\text { laudāti sīmus } \\
\text { sītis } \\
\text { sint }\end{array}$ \\
\hline Pluscuamperfecto & $\begin{array}{l}\text { laudātus essem } \\
\text { essēs } \\
\text { esset } \\
\text { laudāti essēmus } \\
\text { essētis } \\
\text { essent }\end{array}$ \\
\hline
\end{tabular}

Continua... 
Viene de página anterior

\begin{tabular}{|c|c|c|}
\hline Infinitivo presente & laudārī & \\
\hline Infinitivo perfecto & laudātus ese & \\
\hline Participio pasado & laudātus ${ }^{16}$ & alab-ado \\
\hline Gerundivo & laudandus & \\
\hline Infinitivo futuro pasivo & laudātum îrī & \\
\hline
\end{tabular}

\section{Comentario sobre la primera conjugación}

Todos los estudiosos sostienen que la primera conjugación el latín es la más rica y que, al pasar a las lenguas romances, continuó, con mucho, siendo la más fecunda. Ménendez Pidal (1905) afirma que esta conjugación latina tomó pocos verbos de las restantes conjugaciones, pero aún se conservan algunos que, proviniendo de otras conjugaciones, fueron asumidas por la primera y, luego, pasaron a los romances. Entre estos verbos tenemos torrēre turrar, mǐnuĕre menguar, mǒllīre mojar, mejěre mear, fiděre fiar. En la primera conjugación de los romances ingresaron, continúa el autor, los verbos de origen germánico como trotten, trotar, witan, guiar.

Debemos observar que, en español, al igual que en latín, la primera conjugación es con mucho la más rica, la más fecunda y la más creativa. Existen dos razones básicas para ello.

1) Todos los verbos nuevos que crea la lengua se acoplan, sin duda, a la primera conjugación. Pongamos unos ejemplos recientes: para dialogar por escrito en redes sociales o en teléfonos celulares decimos textear o chatear (del inglés text y chat, respectivamente). Y lo mismo sucede en la lengua popular y en la lengua culta cuando derivan verbos de sustantivos. Cuando el campesino sale a cazar tacuacines dice: vamos a tacuacinear... En todos estos ejemplos de verbalización de sustantivos o de neologismos verbales observamos la presencia de un morfema latino, -ear. Este morfema su-

16 En la formación del participio pasivo latino existen dos posibilidades. La mayoría de los verbos lo hacen como laudat-us, esto es, agregan el morfema -us, y el mismo se declina siguiente el modelo de la primera y segunda declinaciones (laudata para nominativo femenino singular, y laudatum para el nominativo neutro singular).Este es el así llamada participio débil. Pero algunos verbos forman este participio de otra manera, esto es, sin la presencia de la oclusiva t en el tema, laudat-us, $-a,-u m$. Este es el caso, por ejemplo, de los verbos mittere (enviar), que hace su participio pasivo fuerte en miss-us, miss-a, miss-um; no en *mitt-us, ${ }^{*}$ mitt-a, ${ }^{*}$ mitt-um, como pareciera esperarse lógicamente. Un buen número de participios en español explicados como irregulares, o considerados como dobles participios, encuentra en el fenómeno del participio fuerte su razón de ser. En realidad, participios como impreso/imprimido, circunciso/ circuncidado, confeso/confesado, fijo/fijado, confuso/confundido, concluido/concluso, obstruido/obstruso, oprimido/opreso, difundido/difuso, dividido/diviso, entre otros, pueden ser explicados como participios fuertes que sobrevivieron en el español, versus la tendencia de la lengua a estandarizar todos los participios bajo el paradigma de los débiles. 
fijo, que "en latín imperial era -ideare", es uno de los recursos más importantes de la lengua española para formar nuevos verbos, sobre todo a partir de sustantivos. (Menéndez Pidal, 1905)

En el habla popular muchas veces este sufijo derivativo, que fonéticamente es un hiato, se transforma en un diptongo, - iar, y así un campesino, cuando rocía en sus cultivos un químico llamado folidol, suele decir: vamos a folidoliar.

2) Es sabido que en español muchas veces podemos formar verbos de la primera conjugación, partiendo de sustantivos, pero utilizando otro morfema. Veamos esto con un ejemplo altamente hipotético. Imaginemos que Honduras se convierte, pronto, en la gran potencia militar y económica de Centroamérica, y que muchos países del área asumen el modo hondureño de vida; entonces podríamos llamar a ese proceso hondure- ñzar, y afirmaríamos que El Salvador se está hondureñizando. El sufijo derivativo que aquí utilizamos para el verbo hondureñiar es el morfema griego -í $\zeta \boldsymbol{\varepsilon} \boldsymbol{v}$ (izein), que ya utilizaban los griegos para la misma estrategia verbal, y que significa imitación. Este morfema derivativo lo encontramos en la formación de muchos verbos en la época helenista, y sobre todo en uno muy popular que se refería al proceso cultural de helenización del Oriente Medio, $\mathbf{\varepsilon} \lambda \boldsymbol{\lambda} \boldsymbol{\eta} \boldsymbol{v} \boldsymbol{i} \zeta \boldsymbol{\varepsilon} \boldsymbol{v} \boldsymbol{v}$ (bellenízein), helenizar, adoptar el patrón griego de vida. ${ }^{17}$ Es muy probable que este sufijo haya pasado al latín imperial bajo la forma de -ideare y que el español lo transformó en el sufijo -ear e-iar, en el habla popular. Según Menéndez Pidal (1905:231), este sufijo fue utilizado en el periodo de decadencia bajo la forma -izare, y "así formó verbos como baptizare, latinizare, etc.”

Tabla 5: La segunda conjugación: monēre (voz activa)

\begin{tabular}{lcc}
\hline Modo indicativo & Latín & Español \\
\hline Presente & mon -eō & Deb -o \\
& -ēs & -es \\
& -et & -e \\
& -ēmus & -emos \\
& -ētis & -éis \\
& -ent & -en
\end{tabular}

Continua...

17 Al sustantivo $\dot{\varepsilon} \lambda \lambda \eta \boldsymbol{v}$, (héllēn, Grecia), se le añadió el morfema $\mathbf{i} \zeta \boldsymbol{\varepsilon} \boldsymbol{\imath} \boldsymbol{v}$, (ízein, imitación o similitud), y de ahí su significado: helenizar 0, en sentido causativo, hacer que otros sigan el patrón cultural griego, especialmente la lengua. 
Viene de página anterior

\begin{tabular}{|c|c|c|}
\hline Pretérito imperfecto & $\begin{array}{c}\text { mon-ēbam } \\
\text {-ēbās } \\
\text {-ēbat } \\
\text {-ēbāmus } \\
\text {-ēbātis } \\
\text {-ēbant }\end{array}$ & $\begin{array}{l}\text { deb-ía } \\
\text {-ías } \\
\text {-ía } \\
\text {-íamos } \\
\text {-íais } \\
\text {-ían }\end{array}$ \\
\hline Futuro imperfecto & $\begin{array}{c}\text { mon-ēbō } \\
\text {-ēbis } \\
\text {-ēbit } \\
\text {-ēbimus } \\
\text {-ēbitis } \\
\text {-ēbunt }\end{array}$ & $\begin{array}{c}\text { Deb -eré } \\
\text {-erás } \\
\text {-erá } \\
\text {-eremos } \\
\text {-eréis } \\
\text {-erán }\end{array}$ \\
\hline Pretérito perfecto & $\begin{array}{l}\text { monu-ī } \\
\text {-istī } \\
\text {-it } \\
\text {-imus } \\
\text {-istis } \\
\text {-ērunt/ēre }\end{array}$ & he debido \\
\hline Pretérito pluscuamperfecto & $\begin{array}{c}\text { monu -eram } \\
\text {-erās } \\
\text {-erat } \\
\text {-erāmus } \\
\text {-erātis } \\
\text {-erant }\end{array}$ & había debido \\
\hline Futuro perfecto & $\begin{array}{l}\text { monu-erō } \\
\text {-eris } \\
\text {-erit } \\
\text {-erimus } \\
\text {-eritis } \\
\text {-erint }\end{array}$ & Habré debido \\
\hline Modo imperativo & $\begin{array}{l}\text { Mon -ē } \\
\text { - ēte } \\
\text { - ētō } \\
\text {-entō }\end{array}$ & $\begin{array}{l}\text { deb-es } \\
\text { deb-éis }\end{array}$ \\
\hline \multicolumn{3}{|l|}{ Modo subjuntivo } \\
\hline Presente & $\begin{array}{l}\text { mon-eam } \\
\text {-eās } \\
\text {-eat } \\
\text {-eāmus } \\
\text {-eātis } \\
\text {-eant }\end{array}$ & $\begin{array}{l}\text { deb-a } \\
\begin{array}{c}\text {-as } \\
\text {-a } \\
\text {-amos } \\
\text {-áis } \\
\text {-an }\end{array}\end{array}$ \\
\hline (Pretérito) Imperfecto & $\begin{array}{c}\text { mon-ērem } \\
\text {-ērēs } \\
\text {-ēret } \\
\text {-ērēmus } \\
\text {-ērētis } \\
\text {-ērent }\end{array}$ & $\begin{array}{c}\text { deb-iera/iese } \\
\text {-ieras } \\
\text {-iera } \\
\text {-ieramos } \\
\text {-iérais } \\
\text {-ieran }\end{array}$ \\
\hline
\end{tabular}


Viene de página anterior

\begin{tabular}{|c|c|c|}
\hline Perfecto & $\begin{array}{l}\text { monu-erim } \\
\text {-eris } \\
\text {-erit } \\
\text {-erimus } \\
\text {-eritis } \\
\text {-erint }\end{array}$ & \\
\hline Pluscuamperfecto & $\begin{array}{c}\text { monu-issem } \\
\text {-issēs } \\
\text {-isset } \\
\text {-issēmus } \\
\text {-issētis } \\
\text {-issent }\end{array}$ & \\
\hline Infinitivo presente & monēre & deb-er \\
\hline Infinitivo perfecto & monu-isse & \\
\hline Participio presente & Monens & \\
\hline Gerundio & monendum & Debiendo \\
\hline Primer supino & monit-um & \\
\hline Segundo supino & monit-ū & \\
\hline Participio futuro & monit-ūrus & \\
\hline
\end{tabular}

Tabla 6: La segunda conjugación: monēre (voz pasiva)

\begin{tabular}{|c|c|c|}
\hline Modo indicativo & Latín & Español \\
\hline Presente & $\begin{array}{c}\text { mon -eor } \\
\text {-ēris } \\
\text {-ētur } \\
\text {-ēmur } \\
\text {-ēminī } \\
\text {-entur }\end{array}$ & \\
\hline Pretérito imperfecto & $\begin{array}{c}\text { Mon -ēbar } \\
\text {-ēbāris } \\
\text {-ēbātur } \\
\text {-ēbāmur } \\
\text {-ēbāminī } \\
\text {-ēbantur }\end{array}$ & \\
\hline Futuro imperfecto & $\begin{array}{c}\text { mon-ēbor } \\
\text {-ēberis } \\
\text {-ēbitur } \\
\text {-ēbimur } \\
\text {-ēbiminī } \\
\text {-ēbuntur }\end{array}$ & \\
\hline
\end{tabular}


AKADEMOS Julio-Diciembre 2015, n. ${ }^{\circ} 25$, ISSN: 1995-4743

Viene de página anterior

\begin{tabular}{|c|c|}
\hline Pretérito perfecto & $\begin{array}{l}\text { monitus sum } \\
\text { es } \\
\text { est } \\
\text { monitī sumus } \\
\text { estis } \\
\text { sunt }\end{array}$ \\
\hline Pretérito pluscuamperfecto & $\begin{array}{l}\text { monitus eram } \\
\text { erās } \\
\text { erat } \\
\text { monitī erāmus } \\
\text { erātis } \\
\text { erant }\end{array}$ \\
\hline Futuro perfecto & $\begin{array}{l}\text { monitus erō } \\
\text { eris } \\
\text { erit } \\
\text { monitī erimus } \\
\text { eritis } \\
\text { erunt }\end{array}$ \\
\hline Modo imperativo & $\begin{array}{l}\text { Mon-ēre } \\
\text {-ēmini } \\
\text {-ētor } \\
\text {-entor }\end{array}$ \\
\hline \multicolumn{2}{|l|}{ Modo subjuntivo } \\
\hline Presente & $\begin{array}{l}\text { mon-ear } \\
\text {-eāris } \\
\text {-eātur } \\
\text {-eāmur } \\
\text {-eāminī } \\
\text {-eantur }\end{array}$ \\
\hline Imperfecto & $\begin{array}{l}\text { mon-ērer } \\
\text {-ērēris } \\
\text {-ērētur } \\
\text {-ērēmur } \\
\text {-ērēminī } \\
\text {-ērentur }\end{array}$ \\
\hline Perfecto & $\begin{array}{l}\text { onitus sim } \\
\text { sis } \\
\text { sit } \\
\text { monitī sīmus } \\
\text { sītis } \\
\text { sint }\end{array}$ \\
\hline
\end{tabular}

Continua... 
Viene de página anterior

\begin{tabular}{lll}
\hline Pluscuamperfecto & $\begin{array}{c}\text { monitus essem } \\
\text { essēs } \\
\text { esset } \\
\text { monitī essēmus } \\
\text { essētis } \\
\text { essent } \\
\text { monērī }\end{array}$ \\
\hline Infinitivo presente & monitus esse & \\
\hline Infinitivo perfecto & monitus & deb-ido \\
\hline Participio pasado & monendum & \\
\hline Gerundivo & monitus ìrī & \\
\hline Infinitivo futuro pasivo & \\
\hline
\end{tabular}

Tabla 7: La tercera conjugación: legere (voz activa)

\begin{tabular}{|c|c|}
\hline Presente & $\begin{array}{c}\text { leg -ō } \\
\text {-is } \\
\text {-it } \\
\text {-imus } \\
\text {-itis } \\
\text {-unt }\end{array}$ \\
\hline Pretérito imperfecto & $\begin{array}{l}\text { leg- ēbam } \\
\text {-ēbās } \\
\text {-ēbat } \\
\text {-ēbāmus } \\
\text {-ēbātis } \\
\text {-ēbant }\end{array}$ \\
\hline Futuro imperfecto & $\begin{array}{c}\text { leg- am } \\
\text {-ēs } \\
\text {-et } \\
\text {-ēmus } \\
\text {-ētis } \\
\text {-ēnt }\end{array}$ \\
\hline Pretérito perfecto & $\begin{array}{l}\text { Lex -ī } \\
\begin{array}{l}\text {-istī } \\
\text {-it } \\
\text {-imus } \\
\text {-istis } \\
\text {-ērunt/ēre }\end{array}\end{array}$ \\
\hline Pretérito pluscuamperfecto & $\begin{array}{l}\text { lex - eram } \\
\text {-erās } \\
\text {-erat } \\
\text {-erāmus } \\
\text {-erātis } \\
\text {-erant }\end{array}$ \\
\hline
\end{tabular}


Viene de página anterior

\begin{tabular}{|c|c|}
\hline Futuro perfecto & 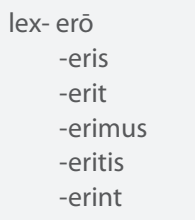 \\
\hline Modo imperativo & $\begin{array}{l}\text { leg -ē } \\
\text { - ite } \\
\text { - itō } \\
\text {-untō }\end{array}$ \\
\hline \multicolumn{2}{|l|}{ Modo subjuntivo } \\
\hline Presente & $\begin{array}{c}\text { leg - am } \\
\text {-ās } \\
\text {-at } \\
\text {-āmus } \\
\text {-ātis } \\
\text {-ant }\end{array}$ \\
\hline Imperfecto & $\begin{array}{l}\text { leg -ërem } \\
\text {-erēs } \\
\text {-eret } \\
\text {-erēmus } \\
\text {-erētis } \\
\text {-erent }\end{array}$ \\
\hline Perfecto & $\begin{array}{l}\text { lex -erim } \\
\quad \text {-eris } \\
\text {-erit } \\
\text {-erimus } \\
\text {-eritis } \\
\text {-erint }\end{array}$ \\
\hline Pluscuamperfecto & $\begin{array}{l}\text { lex- issem } \\
\text {-issēs } \\
\text {-isset } \\
\text {-issēmus } \\
\text {-issētis } \\
\text {-issent }\end{array}$ \\
\hline Infinitivo presente & legere \\
\hline Infinitivo perfecto & lex-isse \\
\hline Participio presente & legens \\
\hline Gerundio & legendum \\
\hline Primer supino & lect-um \\
\hline Segundo supino & lect-ū \\
\hline Participio futuro & lect-ūrus \\
\hline
\end{tabular}


Tabla 8: La tercera conjugación: legere (voz pasiva)

\begin{tabular}{|c|c|c|}
\hline Modo indicativo & Latín & Español \\
\hline Presente & $\begin{array}{l}\text { leg -or } \\
\text {-eris } \\
\text {-itur } \\
\text {-imur } \\
\text {-iminī } \\
\text {-untur }\end{array}$ & \\
\hline Pretérito imperfecto & $\begin{array}{l}\text { leg -ēbar } \\
\text {-ēbāris } \\
\text {-ēbātur } \\
\text {-ēbāmur } \\
\text {-ēbāminī } \\
\text {-ēbantur }\end{array}$ & \\
\hline Futuro imperfecto & $\begin{array}{l}\text { leg -ar } \\
\text {-ēris } \\
\text {-ētur } \\
\text {-ēmur } \\
\text {-ēminī } \\
\text {-entur }\end{array}$ & \\
\hline Pretérito perfecto & $\begin{array}{l}\text { lectus sum } \\
\text { es } \\
\text { est } \\
\text { lecti sumus } \\
\text { estis } \\
\text { sunt }\end{array}$ & \\
\hline Pretérito pluscuamperfecto & $\begin{array}{l}\text { lectus eram } \\
\text { erās } \\
\text { erat } \\
\text { monitī erāmus } \\
\text { erātis } \\
\text { erant }\end{array}$ & \\
\hline Futuro perfecto & $\begin{array}{l}\text { lectus erō } \\
\text { eris } \\
\text { erit } \\
\text { lecti erimus } \\
\text { eritis } \\
\text { erunt }\end{array}$ & \\
\hline Modo imperativo & $\begin{array}{l}\text { leg -ere } \\
\text {-imini } \\
\text {-itor } \\
\text {-untor }\end{array}$ & \\
\hline Modo subjuntivo & & \\
\hline
\end{tabular}

Continua... 
Viene de página anterior

\begin{tabular}{|c|c|}
\hline Presente & $\begin{array}{l}\text { leg -ar } \\
\text {-āris } \\
\text {-ātur } \\
\text {-āmur } \\
\text {-āminī } \\
\text {-antur }\end{array}$ \\
\hline Imperfecto & $\begin{array}{l}\text { leg -ērer } \\
\text {-erēris } \\
\text {-erētur } \\
\text {-erēmur } \\
\text {-erēminī } \\
\text {-erentur }\end{array}$ \\
\hline Perfecto & $\begin{array}{l}\text { lectus sim } \\
\text { sis } \\
\text { sit } \\
\text { lecti sìmus } \\
\text { sītis } \\
\text { sint }\end{array}$ \\
\hline Pluscuamperfecto & $\begin{array}{l}\text { lectus essem } \\
\text { essēs } \\
\text { esset } \\
\text { lecti essēmus } \\
\text { essētis } \\
\text { essent }\end{array}$ \\
\hline Infinitivo presente & Legī \\
\hline Infinitivo perfecto & lectus esse \\
\hline Participio pasado & lectus \\
\hline Gerundivo & legendus \\
\hline Infinitivo futuro pasivo & lectus ìrī \\
\hline
\end{tabular}

\section{Comentario sobre la segunda y la tercera conjugaciones}

La segunda y la tercera conjugaciones en latín -monēre y legĕre- se caracterizan por llevar una ê larga, la segunda; mientras que la tercera por tener una ĕ breve. Muchos autores piensan que una de las características principales del vocalismo latino sea la oposición entre longitud y brevedad vocá- licas. Con razón, San Agustín refiere que los africanos confundían las palabras latinas ǒs (o breve, bueso) y ōs (o larga, boca); la diferencia entre ambas vocales es puramente de cantidad. Sin embargo, para un hablante de latín clásico resultaba obvia la diferencia fonética entre $\overline{\mathrm{e}}$ y ĕ; con el tiempo, no obstante, esta diferencia fue desapareciendo entre los hablantes. Menéndez Pidal (1905) nos informa que el latín vacilaba en algunos verbos de la segun- 
da y la tercera conjugaciones, y que en varios romances se observa el paso de ě a è. Mas fue en el latín vulgar de España (excepto en Cataluña), no obstante, donde se observa la fu- sión de ambas conjugaciones, que hoy es un hecho en nuestra lengua. En español estas dos conjugaciones terminaron fundiéndose en la segunda.

Tabla 9: La cuarta conjugación: audīre (voz activa)

\begin{tabular}{|c|c|c|}
\hline Modo indicativo & Latín & Español \\
\hline Presente & $\begin{array}{l}\text { aud -iō } \\
\text {-īs } \\
\text {-it } \\
\text {-īmus } \\
\text {-ītis } \\
\text {-iunt }\end{array}$ & $\begin{array}{l}\text { viv -o } \\
\text {-es } \\
\text {-e } \\
\text {-imos } \\
\text {-ís } \\
\text {-en }\end{array}$ \\
\hline Pretérito imperfecto & $\begin{array}{c}\text { aud-iēbam } \\
\text {-ēbās } \\
\text {-ēbat } \\
\text {-ēbāmus } \\
\text {-ēbātis } \\
\text {-ēbant }\end{array}$ & $\begin{array}{l}\text { viv - ía } \\
\text {-ías } \\
\text {-ía } \\
\text {-íamos } \\
\text {-íais } \\
\text {-ían }\end{array}$ \\
\hline Futuro imperfecto & $\begin{array}{c}\text { aud-iam } \\
\text {-iēs } \\
\text {-ièt } \\
\text {-iēmus } \\
\text {-iētis } \\
\text {-ient }\end{array}$ & $\begin{array}{l}\text { viv-iré } \\
\text {-irás } \\
\text {-irá } \\
\text {-iremos } \\
\text {-iréis } \\
\text {-irán }\end{array}$ \\
\hline $\begin{array}{l}\text { Pretérito perfecto } \\
\text { Tema: }\end{array}$ & $\begin{array}{l}\text { audīv-ī } \\
\text {-istī } \\
\text {-it } \\
\text {-imus } \\
\text {-istis } \\
\text {-ērunt/ēre }\end{array}$ & he vivido \\
\hline Pretérito pluscuamperfecto & $\begin{array}{c}\text { audīv-eram } \\
\text {-erās } \\
\text {-erat } \\
\text {-erāmus } \\
\text {-erātis } \\
\text {-erant }\end{array}$ & había vivido \\
\hline Futuro perfecto & $\begin{array}{c}\text { audīv -erō } \\
\text {-eris } \\
\text {-erit } \\
\text {-erimus } \\
\text {-eritis } \\
\text {-erint }\end{array}$ & habré vivido \\
\hline
\end{tabular}


Viene de página anterior

\begin{tabular}{|c|c|c|}
\hline Modo imperativo & $\begin{array}{l}\text { aud-ī } \\
\text { - ìte } \\
\text { - ìtō } \\
\text {-iuntō }\end{array}$ & $\begin{array}{l}\text { viv-e } \\
\text { viv-íd }\end{array}$ \\
\hline \multicolumn{3}{|l|}{ Modo subjuntivo } \\
\hline Presente & $\begin{array}{c}\text { aud -iam } \\
\text {-iās } \\
\text {-iat } \\
\text {-iāmus } \\
\text {-iātis } \\
\text {-iant }\end{array}$ & $\begin{array}{l}\text { viv -a } \\
\text {-as } \\
\text {-a } \\
\text {-amos } \\
\text {-íd } \\
\text {-an }\end{array}$ \\
\hline (Pretérito) Imperfecto & $\begin{array}{c}\text { aud -ïrem } \\
\text {-ïrēs } \\
\text {-ïret } \\
\text {-irēmus } \\
\text {-irētis } \\
\text {-irrent }\end{array}$ & $\begin{array}{l}\text { viv-iera/ieses } \\
\text {-ieras } \\
\text {-iera } \\
\text {-iéramos } \\
\text {-iérais } \\
\text {-ieran }\end{array}$ \\
\hline Perfecto & $\begin{array}{l}\text { audiv-erim } \\
\text {-eris } \\
\text {-erit } \\
\text {-erimus } \\
\text {-eritis } \\
\text {-erint }\end{array}$ & \\
\hline Pluscuamperfecto & $\begin{array}{c}\text { audīv-issem } \\
\text {-issēs } \\
\text {-isset } \\
\text {-issēmus } \\
\text {-issētis } \\
\text {-issent }\end{array}$ & \\
\hline Infinitivo presente & audīe & viv-ere \\
\hline Infinitivo perfecto & audīv-isse & \\
\hline Participio presente & aud-iens & ${ }^{*}$ viviente $^{18}$ \\
\hline Gerundio & aud-iendum & Viviendo \\
\hline Primer supino & audīt-um & \\
\hline Segundo supino & audit-ū & \\
\hline Participio futuro & audīt-ūrus & \\
\hline
\end{tabular}

18 En español desapareció por completo el participio presente activo, quedando únicamente el participio pasivo. Cuando se emplea viviente, que histórica y morfológicamente es un participio activo -lo mismo que durmiente, combatiente, cantante, andante, ambulante, caminante, vidente, oyente, entre otros-, en su uso no hay conciencia de que se trate de una forma verbal, esto es, esas formas lingüísticas están desvinculadas del verbo del que históricamente provienen, y aparecen en la lengua como formas sueltas. 
Tabla 10: La cuarta conjugación: audire (voz pasiva)

\begin{tabular}{|c|c|c|}
\hline Modo indicativo & Latín & Español \\
\hline Presente & $\begin{array}{c}\text { aud -ior } \\
\text {-iris } \\
\text {-ìtur } \\
\text {-ĩmur } \\
\text {-ĩminī } \\
\text {-iuntur }\end{array}$ & \\
\hline Pretérito imperfecto & $\begin{array}{l}\text { aud-iēbar } \\
\text {-iēbāris } \\
\text {-iēbātur } \\
\text {-iēbāmur } \\
\text {-iēbāminī } \\
\text {-iēbantur }\end{array}$ & \\
\hline Futuro imperfecto & $\begin{array}{l}\text { aud-iar } \\
\begin{array}{l}\text {-iēris } \\
\text {-iētur } \\
\text {-iēmur } \\
\text {-iēminī } \\
\text {-ientur }\end{array}\end{array}$ & \\
\hline Pretérito perfecto & $\begin{array}{l}\text { audītus sum } \\
\text { es } \\
\text { est } \\
\text { audīiti sumus } \\
\text { estis } \\
\text { sunt }\end{array}$ & \\
\hline Pretérito pluscuamperfecto & $\begin{array}{l}\text { audītus eram } \\
\text { erās } \\
\text { erat } \\
\text { audīti erāmus } \\
\text { erātis } \\
\text { erant }\end{array}$ & \\
\hline Futuro perfecto & $\begin{array}{l}\text { audītus erō } \\
\text { eris } \\
\text { erit } \\
\text { audīti erimus } \\
\text { eritis } \\
\text { erunt }\end{array}$ & \\
\hline Modo imperativo & $\begin{array}{l}\text { aud -īre } \\
\text {-īmini } \\
\text {-ītor } \\
\text {-iuntor }\end{array}$ & \\
\hline
\end{tabular}

Continua... 
Viene de página anterior

\begin{tabular}{|c|c|}
\hline Presente & $\begin{array}{l}\text { aud -iar } \\
\text {-iāris } \\
\text {-iātur } \\
\text {-iāmur } \\
\text {-iāminī } \\
\text {-iantur }\end{array}$ \\
\hline Imperfecto & $\begin{array}{l}\text { aud -ïrer } \\
\text {-ïrēris } \\
\text {-ïrētur } \\
\text {-ïrēmur } \\
\text {-ïrēminī } \\
\text {-ïrentur }\end{array}$ \\
\hline Perfecto & $\begin{array}{l}\text { audītus sim } \\
\text { sis } \\
\text { sit } \\
\text { audīti sīmus } \\
\text { sìtis } \\
\text { sint }\end{array}$ \\
\hline Pluscuamperfecto & $\begin{array}{l}\text { audītus essem } \\
\text { essēs } \\
\text { esset } \\
\text { audīti essēmus } \\
\text { essētis } \\
\text { essent }\end{array}$ \\
\hline Infinitivo presente & audirī \\
\hline Infinitivo perfecto & audītus esse \\
\hline Participio pasado & audītus \\
\hline Gerundivo & aundiendus \\
\hline Infinitivo futuro pasivo & audītum īrī \\
\hline
\end{tabular}

Tabla 11: La conjugación mixta: capere (voz activa)

\begin{tabular}{lcc}
\hline Modo indicativo & Latín & Español \\
\hline Presente & cap-iō & \\
& -is & \\
& -it & \\
& -imus & \\
& -ītis & \\
& -iunt
\end{tabular}


Viene de página anterior

\begin{tabular}{|c|c|}
\hline Pretérito imperfecto & $\begin{array}{c}\text { cap-iēbam } \\
\text {-ēbās } \\
\text {-ēbat } \\
\text {-ēbāmus } \\
\text {-ēbātis } \\
\text {-ēbant }\end{array}$ \\
\hline Futuro imperfecto & $\begin{array}{c}\text { cap-iam } \\
\text {-iēs } \\
\text {-iet } \\
\text {-iēmus } \\
\text {-iētis } \\
\text {-ient }\end{array}$ \\
\hline Pretérito perfecto & $\begin{array}{l}\text { cēp-ī } \\
\text {-istī } \\
\text {-it } \\
\text {-imus } \\
\text {-istis } \\
\text {-ērunt/ēre }\end{array}$ \\
\hline Pretérito pluscuamperfecto & $\begin{array}{c}\text { cēp-eram } \\
\text {-erās } \\
\text {-erat } \\
\text {-erāmus } \\
\text {-erātis } \\
\text {-erant }\end{array}$ \\
\hline Futuro perfecto & $\begin{array}{c}\text { cēp -erō } \\
\text {-eris } \\
\text {-erit } \\
\text {-erimus } \\
\text {-eritis } \\
\text {-erint }\end{array}$ \\
\hline Modo imperativo & $\begin{array}{l}\text { cap-ī } \\
\text { - ìte } \\
\text { - ìtō } \\
\text {-iuntō }\end{array}$ \\
\hline \multicolumn{2}{|l|}{ Modo subjuntivo } \\
\hline Presente & $\begin{array}{c}\text { cap-iam } \\
\text {-iās } \\
\text {-iat } \\
\text {-iāmus } \\
\text {-iātis } \\
\text {-iant }\end{array}$ \\
\hline Imperfecto & $\begin{array}{c}\text { cap-īrem } \\
\text {-īrēs } \\
\text {-īret } \\
\text {-īrēmus } \\
\text {-īrētis } \\
\text {-īrent }\end{array}$ \\
\hline
\end{tabular}

Continua... 
Viene de página anterior

\begin{tabular}{|l|c|c|}
\hline Cēp-erim & -eris \\
Perfecto & -erit \\
& -erimus \\
& -eritis \\
& -erint \\
\hline Pluscuamperfecto & cēp-issem \\
& -issēs \\
& -isset \\
& -issēmus \\
& -issētis \\
& -issent \\
\hline Infinitivo presente & Capīre \\
\hline Infinitivo perfecto & cēp-isse \\
\hline Participio presente & cap-iens \\
\hline Gerundio & cap-iendum \\
\hline Primer supino & capt-um \\
\hline Segundo supino & capt-ū \\
\hline Participio futuro & capt-ūrus \\
\hline
\end{tabular}

Tabla 12: La conjugación mixta: capire (voz pasiva)

\begin{tabular}{|c|c|c|}
\hline Modo indicativo & Latín & Español \\
\hline Presente & $\begin{array}{c}\text { cap-ior } \\
\text {-īris } \\
\text {-ītur } \\
\text {-īmur } \\
\text {-īminī } \\
\text {-iuntur }\end{array}$ & \\
\hline Pretérito imperfecto & $\begin{array}{c}\text { cap-iēbar } \\
\text {-iēbāris } \\
\text {-iēbātur } \\
\text {-iēbāmur } \\
\text {-iēbāminī } \\
\text {-iēbantur }\end{array}$ & \\
\hline Futuro imperfecto & $\begin{array}{c}\text { cap-iar } \\
\text {-iēris } \\
\text {-iētur } \\
\text {-iēmur } \\
\text {-iēminī } \\
\text {-ientur }\end{array}$ & \\
\hline
\end{tabular}


Viene de página anterior

\begin{tabular}{|c|c|}
\hline Pretérito perfecto & $\begin{array}{l}\text { captus sum } \\
\text { es } \\
\text { est } \\
\text { capti sumus } \\
\text { estis } \\
\text { sunt }\end{array}$ \\
\hline Pretérito pluscuamperfecto & $\begin{array}{l}\text { captus eran } \\
\text { erās } \\
\text { erat } \\
\text { capti erāmus } \\
\text { erātis } \\
\text { erant }\end{array}$ \\
\hline Futuro perfecto & $\begin{array}{l}\text { audītus erō } \\
\text { eris } \\
\text { erit } \\
\text { capti erimus } \\
\text { eritis } \\
\text { erunt }\end{array}$ \\
\hline Modo imperativo & $\begin{array}{l}\text { cap -īre } \\
\text {-īmini } \\
\text {-ītor } \\
\text {-iuntor }\end{array}$ \\
\hline \multicolumn{2}{|l|}{ Modo subjuntivo } \\
\hline Presente & $\begin{array}{l}\text { cap-iar } \\
\text {-iāris } \\
\text {-iātur } \\
\text {-iāmur } \\
\text {-iāminī̄ } \\
\text {-iantur }\end{array}$ \\
\hline Imperfecto & $\begin{array}{l}\text { cap-īrer } \\
\text {-īrēris } \\
\text {-īrētur } \\
\text {-īrēmur } \\
\text {-īrēminī } \\
\text {-īrentur }\end{array}$ \\
\hline Perfecto & $\begin{array}{l}\text { captus sim } \\
\text { sis } \\
\text { sit } \\
\text { capti sīmus } \\
\text { sìtis } \\
\text { sint }\end{array}$ \\
\hline Pluscuamperfecto & $\begin{array}{l}\text { captus essem } \\
\text { essēs } \\
\text { esset } \\
\text { capti essēmus } \\
\text { essētis } \\
\text { essent }\end{array}$ \\
\hline
\end{tabular}

Continua... 
Viene de página anterior

\begin{tabular}{ll}
\hline Infinitivo presente & Capīrī \\
\hline Infinitivo perfecto & captus esse \\
\hline Participio pasado & Captus \\
\hline Gerundivo & capiendus \\
\hline Infinitivo futuro pasivo & captum īī̄ \\
\hline
\end{tabular}

\section{Parte segunda: comparación de la conjugación latina y española}

\section{Sobre la formación del perfecto latino}

En latín, al igual que en griego, se conocen dos maneras para formar el perfecto. La primera de ellas y la más convencional es la formación del así llamado perfecto débil, el cual consiste en que al lexema verbal se le añade un infijo, y luego vienen los morfemas propios. Por ejemplo, para la formación del perfecto de laudāre, tomamos el lexema land $+\overline{\mathrm{a}}$ (vocal temática) $+v$ (infijo del perfecto), y ello constituye el tema del perfecto; a esto adjuntamos los morfemas apropiados y tenemos las diferentes formas del perfecto. Así, si al tema del perfecto laudav-añadimos el morfema - imus, tenemos laudāv-imus, el pretérito perfecto indicativo activo de la primera persona plural. ¿Cómo lo sabemos? Por la presencia del infijo " $v$ " sabemos que estamos ante un perfecto, mientras que por el morfema trabado -imus nos damos cuenta de que se trata de una primera persona plural. Que se trata de la voz activa se sabe por la ausencia de marcas morfológicas que indiquen voz pasiva.
De esta manera se forma el perfecto débil, que es común a la primera y a la cuarta conjugaciones latinas; pero existe otra manera de formar el perfecto, y que es propio de las conjugaciones restantes; se trata del así llamado perfecto fuerte.

El perfecto fuerte se forma añadiendo al lexema verbal el infijo $-u$-, al que luego se anexan los morfemas apropiados. Así, en el caso del verbo monēre, al lexema mon- añadimos el morfema -u-, y con ello tenemos el tema del perfecto: monu-, al que podemos anexar los morfemas pertinentes para la formación de las distintas formas del perfecto. Por ejemplo, si deseo formar el pretérito pluscuamperfecto indicativo activo de la primera persona singular, al referido tema le adjunto el morfema -eram, y entonces tengo la forma monueram: yo habia advertido. Esto mismo sucede con la tercera conjugación, que para el caso hemos utilizado como ejemplo el verbo legěre. El tema del perfecto de este verbo es lex-, y al mismo añadimos los morfemas propios y construimos así las diferentes formas del perfecto. De esta manera, si quisiera formar el subjuntivo perfecto activo de la tercera persona singular, al tema 
del perfecto, lex-, debo añadirle el morfema -erit, y así tendríamos lex-erit, que él haya leído.

\section{Modos verbales presentes únicamente en español}

En sentido estricto, solo hay dos formas del español que no están presentes en latín: el potencial simple (amaría) y su forma perifrástica (habría amado), así como el pretérito anterior o indefinido (amê). En cuanto al potencial, este puede ser explicado de la siguiente manera: el latín expresa esas ideas con el subjuntivo perfecto y pluscuamperfecto. El potencial, como sabemos, es inexistente en latín, y a este respecto Menéndez Pidal (1905) afirma que el español se enriqueció con tiempos que en latín no existían, como he amado, hubiese amado, amaría, habría amado.

El pretérito indefinido (amè). El latín desconoce el tiempo aoristo, que sí encontramos en griego, y con el que se expresa la temporalidad de una acción conclusa. El latín, al insistir en el aspecto de la acción verbal más que en su temporalidad, deja al contexto la idea de una acción temporalmente conclusa, la que suele expresar con el pretérito perfecto. Así, laudāvi podría significar he alabado o alabé. ¿De dónde surgió alabe? En el latín vulgar, el perfecto am $\bar{a} v i$ poco a poco fue perdiendo el infijo $v$, y se fue imponiendo la forma amai que el romance heredó. $\mathrm{Al}$ respecto, Menéndez Pidal refiere que la forma ordinaria -āvi fue olvidada en latín vulgar, el cual contrajo en una las dos sílabas de esta terminación, como ya hacía a veces el latín literario. Está documentado el perfecto cantāvi, pero también cantāi y, así mismo, el perfecto dormīvi y dormīi.
De lo anterior queda constancia en el italiano, que construye el perfecto ho amato (he amado) y, a su vez, el pretérito indefinido amai (amé), al que Lázaro y Tusón (1989: 6) prefieren llamar perfecto simple. En español, en cambio, la forma se transformó en amé, pero siempre se conservó el perfecto perifrástico be amado.

La ausencia de un pretérito indefinido en latín -ya dijimos que esta significación verbal la asume el pretérito perfecto- plantea problemas adicionales. En la lengua griega, a diferencia del latín, sí encontramos una forma especial para expresar la idea de una acción acaecida en un tiempo indeterminado; se trata del así llamado tiempo aoristo. A propósito del aoristo, Morwood (2002: 61) señala: "This tense simply tells us that a single event happened in the past". Pero esto se refiere específicamente al aoristo indicativo. Pero sabemos que hay otros aoristos: participio, infinitivo, imperativo, subjuntivo y optativo; en estos casos el aoristo no indica temporalidad en que sucede un acontecimiento, sino singularidad de la acción. (Ibid.)

El gran filólogo alemán Max Zerwick (1974) nos aclara mejor el significado del aoristo en la lengua griega. Dice el gran sabio que una descripción puede servirnos para enriquecer, explicar o adornar un concepto; pero si se hace lo mismo en términos gramaticales eso constituye una limitación. Si decimos, por ejemplo, que un adjetivo modifica al sustantivo; podríamos afirmar que el sustantivo mesa incluye a cualquier mesa; si, por el contrario, a mesa le añado un adjetivo, y digo mesa redon$d a$; esta excluye otras clases de mesa. Si añado 
otros adjetivos y expreso mesa redonda y limpia, limito más su aplicación. Esto mismo, dice el gran profesor, sucede con el aoristo en la lengua griega, como su mismo nombre nos lo indica -aoristo viene de $\boldsymbol{\alpha}+\boldsymbol{o} \boldsymbol{\varrho o s}$ ( $\sin$ límites o determinaciones)-, y significa lo siguiente: lo indeterminado, en el sentido de no implicar continuidad o repetición (como el imperfecto), pero tampoco persistencia en el presente (como el perfecto). En resumen, agrega Zerwick, el aoristo no expresa duración; pero tampoco la excluye. El aoristo ve simplemente la acción como algo puntual, o punctiliar, como se expresa esta idea en inglés. Usando una figura geométrica, el aoristo puede ser visto como el punto central de un círculo que el verbo nunca describe, pero que se puede conocer "por el contexto o por una inferencia lógica”. (1974: iii)

El griego también conoce el pretérito perfecto, al igual que el latín y el español, y con él expresa una acción ya realizada o cumplida; pero los resultados de la acción están presentes en el momento del hablante. En realidad, sostiene Zerwick, el pretérito perfecto en griego es más bien un presente. El pretérito perfecto poco tiene que ver con su par inglés o español, encontrado en oraciones como yo he estado en Roma hace muchos años. (Zerwick, 1974: xxiv)

En cuanto al pretérito perfecto latino y español, entonces, podríamos decir que no son equivalentes entre ellos en lo que se refiere a su significado; pero tampoco coinciden con el significado del pretérito perfecto griego; en este sentido tiene razón Vineis (1995: 394) cuando afirma que el pretérito perfecto latino "asume funciones propias de aoristo y del perfecto, que confluyeron en él formalmente". Además, debe decirse que el pretérito indefinido español-que es una forma evolucionada del pretérito perfecto latino- tiene muy poco que ver con la idea del aoristo indicativo griego. En este sentido, bien podrían ser ciertas las palabras de Menéndez Pidal cuando afirma que el verbo latino era un estado empobrecido del verbo indoeuropeo.

En fin, el griego y el latín son lenguas altamente complejas en la morfología del verbo y del sustantivo, así como en la sintaxis; por eso ambas podían expresar ideas extremadamente complejas con la riqueza de su forma verbal; probablemente estas expresiones lingüísticas eran más sutiles que las nuestras, sin que esta proposición indique una adhesión a la idea de W. von Humboldt sobre la superioridad de este tipo de lenguas con respecto a las lenguas sin flexión.

\section{Elpotencial}

Menéndez Pidal (1905: 179) observa que el verbo latino representaba "un estado empobrecido del verbo indo-europeo, pues carecía de la voz media, del modo optativo, del número dual, continuó empobreciéndose en latín vulgar, sustituyendo varias formas sintéticas por otras analíticas". La ausencia del optativo -que sí está presente en griego- puede explicarse de la misma manera en que se explicó la ausencia del aoristo: el latín hizo confluir el aoristo y el perfecto, así como fusionó los modos subjuntivo y optativo. (Vineis, 1995) 
Pero el romance no sólo significó un empobrecimiento del verbo latino, que ya estaba empobrecido, sino que de alguna manera también implicó riqueza, puesto que aparecieron nuevos modos y nuevas formas desconocidas en el latín; la más importante de estas formas quizás sea el potencial.

En español tenemos dos formas del potencial: amaría (simple) y habría amado (compuesta). Este modo verbal es desconocido en latín. ¿De dónde lo tomó el español? Lapesa (1981) refiere que así como cantare habeo dio lugar al futuro imperfecto español, igualmente la forma cantare habebam dio paso al condicional, cantaría.

\section{La vozpasiva}

Varios estudiosos piensan que en la formación del pasivo las lenguas romances hicieron todo ex novo. De hecho, todas las formas simples o sintéticas de la voz pasiva latina fueron eliminadas (Lapesa, 1981). Así, el indicativo presente pasivo latino, laudatur, se sustituyó por la forma analítica o perifrástica es alabado. Prácticamente solo fue conservado el participio pasivo latino, laudatus, alabado.

Pero sabemos que no solo el romance procedió a sustituir las formas sintéticas por formas analíticas. Ya en el latín vulgar se observa esa sustitución; así, aunque exista la forma sintética laudatur, es alabado; el latín vulgar suele sustituirla por la perífrasis laudatus est. En este sentido, el romance únicamente continuó una línea de desarrollo de la morfología del verbo, que ya había iniciado el latín vulgar.

\section{Conclusión}

Podemos decir, con Menéndez Pidal (1905: 178), que "La conjugación fue conservada por el romance en muy buen estado, contrastando con el olvido de la declinación". Al contrario de la conjugación, las desinencias de los casos de la declinación "resultaron instrumento inservible en romance". A la conservación de las desinencias verbales pudo haber contribuido el hecho de que estas eran "completamente claras", no así las desinencias de los casos de la declinación.

De acuerdo con lo anterior, luego, el español conservó en lo fundamental la morfología del verbo latino, especialmente la de la voz activa. Su gran innovación en este sentido pudo estar en la creación de la voz pasiva, pero bajo formas analíticas o perifrásticas. En la voz activa, en cambio, su novedad estaría en la creación de un modo potencial y en el pretérito indefinido, con un uso muy parecido al aoristo indicativo griego.

Muchos de los cambios en la morfología del verbo que observamos en español con respecto al latín, no obstante, ya eran observables en el desarrollo del latín vulgar, y en algunos casos hasta en el latín literario.

Existen, entonces, dos cosas del latín muy bien conservadas en español: actualmente se reconoce que el español conservó en lo fundamental el léxico latino -muchos estudiosos estiman que entre el $80 \%$ y el $85 \%$ del vocabulario español deriva del latín-; a ello debemos añadir la conservación de la forma fundamental del verbo. 


\section{Referencia bibliográfica}

1. Errandonea, I. (1942). Gramática sucinta de la lengua griega. Barcelona: Editorial Pontificia.

2. Henle, R. (1958). Latin Grammar. Chicago: Loyola Press.

3. Janssens, J. (ed.). (1990). Ars legendi. Roma: Pontificia Università Gregoriana.

4. Kinchin, F. (ed.). (1948). Latin. Suffolk (Great Britain): The Chaucer Press.

5. Lapesa, R. (1981). Historia de la lengua española. Madrid: Gredos.

6. Lázaro, F. \& Tusón, V. (1989). Lengua española. Madrid: Grupo Anaya.

7. Martínez Bigorra, S. (ed.). (1976). Lengua Latina. Tomo I. Madrid: Universidad Nacional de Educación a Distancia.

8. Menéndez Pidal, R. (1905). Manual de gramática histórica. Madrid: Librería General de Victoriano Suárez.

9. Monteil, P. (2003). Elementos de fonética y morfología del latín. Sevilla: Universidad de Sevilla.
10. Morwood, J. (2001). Oxford Grammar of Classical Greek. Oxford: University Press.

11. Obediente Sosa, E. (2000). Biografía de una lengua. Cartago (Costa Rica): Libro Universitario Regional.

12. Ramat, A. G. y Ramat, P. (Eds.). (1995). Las lenguas indoeuropeas. Madrid: Cátedra.

13. Seco, M. (1994). Gramática esencial del español. México: Espasa Calpe.

14. Tagliavini, C. (1973). Orígenes de las lenguas neolatinas. México: Fondo de Cultura Económica.

15. Vineis, E. (1995). Latín. En Ramat, A. G. y Ramat, P. (Eds.). Las lenguas indoeuropeas, pp. 347-419. Madrid: Cátedra.

15. Watkings, C. (1995). El protoindoeuropeo. En Ramat, A. G. y Ramat, P. (Eds.). Las lenguas indoeuropeas, pp. 57-117. Madrid: Cátedra.

17. Zerwick, M. (1974). A Grammatical Analysis of the Greek New Testament. Rome: Pontifical Biblical Institute. 